\title{
Serotonergic antidepressant use and morbidity and mortality among older adults with COPD
}

\author{
Nicholas T. Vozoris ${ }^{1,2,3}$, Xuesong Wang ${ }^{4}$, Peter C. Austin ${ }^{4,5}$, \\ Anne L. Stephenson ${ }^{1,2,3,5}$, Denis E. O'Donnell ${ }^{6}$, Andrea S. Gershon ${ }^{3,4,5,7}$, \\ Sudeep S. Gill ${ }^{4,6}$ and Paula A. Rochon $3,4,5,8$
}

Affiliations: 'Division of Respirology, Dept of Medicine, St Michael's Hospital, Toronto, ON, Canada. ${ }^{2}$ Keenan Research Centre in the Li Ka Shing Knowledge Institute, St Michael's Hospital, Toronto, ON, Canada. ${ }^{3}$ Dept of Medicine, University of Toronto, Toronto, ON, Canada. ${ }^{4}$ Institute for Clinical Evaluative Sciences, Toronto, ON, Canada. ${ }^{5}$ Institute of Health Policy, Management, and Evaluation, University of Toronto, Toronto, ON, Canada. ${ }^{6}$ Dept of Medicine, Queen's University, Kingston, ON, Canada. ${ }^{7}$ Sunnybrook Hospital, Dept of Medicine, Toronto, ON, Canada. ${ }^{8}$ Women's College Research Institute, Women's College Hospital, Toronto, ON, Canada.

Correspondence: Nicholas T. Vozoris, Division of Respirology, Dept of Medicine, St Michael's Hospital, 30 Bond Street, Toronto, ON, Canada, M5B 1W8. E-mail: nick.vozorisQutoronto.ca

@ERSpublications

Serotonergic antidepressants are associated with increased adverse respiratory outcomes in older adults with COPD http://ow.ly/E5ex30khSLq

Cite this article as: Vozoris NT, Wang X, Austin PC, et al. Serotonergic antidepressant use and morbidity and mortality among older adults with COPD. Eur Respir J 2018; 52: 1800475 [https://doi.org/10.1183/ 13993003.00475-2018].

ABSTRACT We evaluated the relationship between new selective serotonin reuptake inhibitor (SSRI) or serotonin-noradrenaline reuptake inhibitor (SNRI) drug use and respiratory-related morbidity and mortality among older adults with chronic obstructive pulmonary disease (COPD).

This was a retrospective population-based cohort study using heath administrative data from Ontario, Canada. Individuals aged $\geqslant 66$ years, with validated, physician-diagnosed COPD $(n=131718)$ were included. New SSRI/SNRI users were propensity score matched 1:1 to controls on 40 relevant covariates to minimise potential confounding.

Among propensity score matched community-dwelling individuals, new SSRI/SNRI users compared to non-users had significantly higher rates of hospitalisation for COPD or pneumonia (hazard ratio (HR) $1.15,95 \%$ CI 1.05-1.25), emergency room visits for COPD or pneumonia (HR 1.13, 95\% CI 1.03-1.24), COPD or pneumonia-related mortality (HR 1.26, 95\% CI 1.03-1.55) and all-cause mortality (HR 1.20, 95\% CI 1.11-1.29). In addition, respiratory-specific and all-cause mortality rates were higher among longterm care home residents newly starting SSRI/SNRI drugs versus controls.

New use of serotonergic antidepressants was associated with small, but significant, increases in rates of respiratory-related morbidity and mortality among older adults with COPD. Further research is needed to clarify if the observed associations are causal or instead reflect unresolved confounding. 


\section{Introduction}

Chronic obstructive pulmonary disease (COPD) is estimated to affect more than $>10 \%$ of individuals aged $\geqslant 40$ years worldwide [1]. Recurrent acute respiratory exacerbations (i.e. sustained worsening of respiratory symptoms that require additional therapy) are common in COPD and are associated with reduced quality of life and increased need for hospitalisation and death [2]. Depression and anxiety frequently occur in COPD (affecting $>70-80 \%$ of individuals) [3-5] and the presence of comorbid psychiatric disease in COPD is known to be associated with increased exacerbation risk and mortality [6, 7]. Serotonergic antidepressants, including selective serotonin reuptake inhibitors (SSRIs) and serotonin-noradrenaline reuptake inhibitors (SNRIs), are recommended as first-line pharmacotherapy for major depression and generalised anxiety disorder $[8,9]$. Depression and anxiety could heighten the perception of respiratory symptoms (such as dyspnoea) in COPD, and by better controlling altered mood, SSRI and SNRI drugs might theoretically indirectly improve respiratory health outcomes in COPD. However, the few clinical trials conducted with individuals with COPD have not clearly demonstrated that SSRI and SNRI drugs are effective for depression and anxiety in this population [10-12]. Furthermore, in a few small trials where SSRI and SNRI drugs were evaluated among individuals with COPD as a direct treatment for advanced-level, refractory dyspnoea, a beneficial effect was not demonstrated [12-14].

There is a theoretical concern that SSRI and SNRI drugs could lead to respiratory harm among individuals with COPD through several potential mechanisms. First, tolerability data from previous randomised controlled trials involving SSRI and SNRI drugs show that an estimated $10-20 \%$ of drug recipients experience side-effects of fatigue and sleepiness [15-19]. Possible resulting drug-related respiratory depression, with hypoxaemia and hypercapnia, could lower the threshold for an acute respiratory exacerbation. Second, an estimated $10-30 \%$ of SSRI and SNRI drug recipients experience side-effects of nausea and vomiting [15-19], which could contribute to aspiration-related respiratory tract infection (especially if compounded by side-effects of fatigue and sleepiness) and result in acute respiratory exacerbation. Third, SSRI and SNRI drugs may predispose to respiratory exacerbation by lowering the threshold for infection through adverse health effects on immune cell quantity and function [20-23]. Finally, increased extracellular concentrations of serotonin (which SSRI and SNRI drugs produce) have been linked to reduced clearance of apoptotic cells [24], which could then lead to inflammation and plugging of the airways [25], and thereby respiratory tract infection and exacerbation. The need for further research into the impact of SSRI/SNRI drugs in COPD has been advocated [10].

The purpose of this study was to evaluate the relationship between new SSRI and SNRI drug use and respiratory-related morbidity and mortality among older adults with COPD.

\section{Methods}

\section{Study design}

This was a population-based, retrospective cohort study using heath administrative data for the province of Ontario (13.5 million people) for the period April 1, 2008 to March 31, 2014.

\section{Data sources}

13 health administrative databases held at the Institute of Clinical Evaluative Sciences were linked at an individual-person level using unique coded identifiers. One database contained individuals with validated, physician-diagnosed COPD. Individuals with COPD were identified by a previously developed, highly-specific algorithm of COPD codes: three or more ambulatory claims for COPD within any 2-year period or one or more COPD hospitalisation(s) (specificity 95.4\%, sensitivity 57.4\%) [26]. A second database was the Ontario Drug Benefit (ODB) database, which contained information on all outpatient drug dispensing to individuals aged $\geqslant 65$ years. Drug claim coding errors in the ODB is very low (0.7\%) [27]. Other databases containing information on ambulatory visits, emergency room (ER) visits, hospitalisations and death are outlined in the online supplementary material.

\section{Study population}

To be included in this study, individuals had to meet the following criteria between April 1, 2008 and December 31, 2013: have validated, physician-diagnosed COPD; be an Ontario resident; and be aged $\geqslant 66$ years. An end enrolment date of December 31, 2013 was selected, so that all individuals included in the study had a 90-day follow-up period (up to the end-of-study date of March 31, 2014) in which to evaluate for outcomes. Although individuals aged $<66$ years were not included (because drug dispensing data were not available for them in the ODB), the majority of individuals with COPD are aged $\geqslant 65$ years [28]. Individuals with claims for palliative care (based on physician service codes) in the year prior to the index date (which is defined below) were excluded, as these individuals are more likely to receive SSRI/SNRI drugs and have poor health outcomes, and their inclusion could then serve to potentially bias results. Individuals living in the community versus in long-term care homes at the time of the index date were 
examined separately, in order to minimise bias, as long-term care home residents would probably have poorer health outcomes and increased chances for drug exposure compared to community-dwelling individuals.

\section{Exposed and control groups with index date definitions}

The exposed group consisted of new SSRI or SNRI drug users, defined (using a previously published approach [29, 30]) as recipients of any SSRI or SNRI drug between April 1, 2008 and December 31, 2013, without having a SSRI or SNRI drug in the year prior. All SSRI and SNRI drugs covered by the ODB were considered (citalopram, duloxetine, escitalopram, fluoxetine, fluvoxamine, paroxetine, sertraline and venlafaxine). New use was only counted once per individual, and if an individual met criteria for new use more than once during the study, then only the first dispensing was considered. We elected to study new, and not prevalent, SSRI/SNRI drug use in order to minimise potential "healthy user" bias associated with prevalent use and since our purpose was to examine for acute-onset drug-related outcomes. The index date for the exposed group was the day of new SSRI/SNRI drug dispensing.

Individuals in the control group received no SSRI or SNRI drug between April 1, 2008 and December 31, 2013. Individuals entered the control group by receiving any other new drug on or before a date chosen randomly from the accrual period. New drug use for the control group was defined as no receipt, within the past year, of a drug within the same class as the index control drug $[29,30]$. If the most recent control drug dispensing took place $>6$ months before the randomly selected date from the accrual period, or if it took place before the start of the 2008-2013 period, then the individual was excluded [29, 30]. The index date for control individuals was the date the new non-SSRI/SNRI drug was dispensed.

\section{Outcomes}

The primary outcome was time to hospitalisation for COPD or pneumonia, since this is a clinically important event among individuals with COPD, as it is associated with significant morbidity and mortality [2]. Secondary outcomes included outpatient respiratory exacerbation (defined as receipt of an oral corticosteroid or respiratory antibiotic within 7 days of a physician clinic/office visit for COPD or pneumonia, with the corticosteroid or antibiotic prescription having a supply of 5-21 days [29, 30]); ER visit for COPD or pneumonia that did not directly result in a hospitalisation; admission to an intensive care unit (ICU) during a hospitalisation for COPD or pneumonia; COPD or pneumonia-related mortality; and all-cause mortality. COPD and pneumonia diagnoses were based on relevant International Classification of Diseases (ICD) codes (e.g. in ICD-10 J41, J42 J43, J44 for COPD and J09-18, J20-22, J40 for pneumonia). All outcomes were evaluated during a 90-day period following the index date. We selected a 90-day follow-up period since it was our intent to examine for acute-onset drug-related outcomes and since it is recognised that it can take up to several weeks before SSRI and SNRI drugs have full effect [31].

\section{Propensity score matching}

Because exposed and control individuals were anticipated to differ on demographic and health characteristics that would influence exposure to SSRI and SNRI drugs and risk for respiratory outcomes, we used 1:1 propensity score matching to create matched samples of exposed and control individuals, in order to reduce bias [32]. A 1:1 matching ratio was selected, since this was previously shown to minimise bias; inclusion of more control individuals resulted in minimal precision increase [33]. Individuals were matched on the logit of the propensity score using a width caliper $0.2 \mathrm{SD}$ of the logit of the propensity score [34]. A propensity score for new SSRI/SNRI drug receipt was developed using a logistic regression model with 40 relevant covariates, including markers of COPD severity (i.e. frequency and recency of prior COPD exacerbation, duration of COPD, receipt of COPD medications), comorbidities, healthcare system use, other relevant prescription drug receipt (i.e. opioids, benzodiazepines, smoking cessation drugs) and demographics. The full list of variables included in the propensity score model can be found in the online supplementary material and an abridged list is shown in table 1.

\section{Sensitivity analyses}

Several sensitivity analyses were performed. First, because COPD exacerbation history is an important marker of disease severity, we evaluated our outcomes stratifying by COPD exacerbation history in the year prior to the index date. International COPD guidelines use COPD exacerbation frequency to distinguish COPD severity [2] and COPD exacerbations are associated with a greater degree of airflow obstruction [35], poorer quality of life [36], future exacerbation risk [37] and mortality [38]. We defined COPD exacerbation history as a three-level, mutually exclusive variable: no exacerbation versus 1 or more outpatient exacerbation, with no exacerbation requiring presentation to hospital versus 1 or more exacerbation requiring presentation to hospital. Second, because having comorbid psychiatric disease in 
TABLE 1 Baseline characteristics of community-dwelling cohort, before and after propensity score matching labridged set of covariates $^{\#}$ )

\begin{tabular}{|c|c|c|c|c|c|c|}
\hline & \multicolumn{3}{|c|}{ Before propensity score matching } & \multicolumn{3}{|c|}{ After propensity score matching } \\
\hline & $\begin{array}{l}\text { New SSRI/ } \\
\text { SNRI users }\end{array}$ & $\begin{array}{l}\text { Non-SSRI/SNRI } \\
\text { users }\end{array}$ & $\begin{array}{l}\text { Standardised } \\
\text { difference }\end{array}$ & $\begin{array}{l}\text { New SSRI/ } \\
\text { SNRI users }\end{array}$ & $\begin{array}{l}\text { Non-SSRI/SNRI } \\
\text { users }\end{array}$ & $\begin{array}{l}\text { Standardised } \\
\text { difference }\end{array}$ \\
\hline Age years & $77.4 \pm 7.2$ & $76.9 \pm 7.5$ & 0.07 & $77.4 \pm 7.2$ & $77.5 \pm 7.7$ & 0.01 \\
\hline Female & 55.7 & 44.9 & 0.22 & 54.6 & 54.5 & 0.0006 \\
\hline \multicolumn{7}{|l|}{$\begin{array}{l}\text { COPD exacerbation frequency past } \\
\text { year }\end{array}$} \\
\hline$\geqslant 1$ outpatient exacerbation & 17.2 & 18.5 & 0.03 & 17.1 & 17.1 & 0 \\
\hline $\begin{array}{l}\geqslant 1 \text { exacerbation requiring } \\
\text { hospital presentation }\end{array}$ & 24.7 & 20.0 & 0.11 & 24.2 & 24.2 & 0 \\
\hline $\begin{array}{l}\text { COPD exacerbation in the past } \\
30 \text { days }\end{array}$ & 9.9 & 10.9 & 0.03 & 10.0 & 9.8 & 0.004 \\
\hline \multicolumn{7}{|l|}{$\begin{array}{l}\text { Duration of COPD year prior to index } \\
\text { date }\end{array}$} \\
\hline \multirow{2}{*}{\multicolumn{7}{|c|}{$\begin{array}{l}\text { Respiratory medications in the past } \\
6 \text { months }\end{array}$}} \\
\hline & & & & & & \\
\hline Short-/long-acting $\beta$-agonists & 40.3 & 36.4 & 0.08 & 39.7 & 39.4 & 0.007 \\
\hline $\begin{array}{l}\text { Short-/long-acting } \\
\text { anticholinergics }\end{array}$ & 41.2 & 39.2 & 0.04 & 40.8 & 40.8 & 0.0003 \\
\hline Inhaled corticosteroids & 12.3 & 12.1 & 0.006 & 12.3 & 12.3 & 0.002 \\
\hline $\begin{array}{l}\text { Combination inhaled } \\
\text { corticosteroid- } \\
\text { long-acting } \beta \text {-agonist inhalers }\end{array}$ & 36.4 & 33.2 & 0.07 & 35.9 & 35.8 & 0.002 \\
\hline Oral corticosteroids & 17.8 & 13.9 & 0.11 & 17.3 & 17.1 & 0.003 \\
\hline Theophylline & 2.2 & 1.8 & 0.03 & 2.2 & 2.2 & 0.003 \\
\hline Respiratory antibiotics & 48.1 & 44.3 & 0.08 & 47.5 & 47.5 & 0.0003 \\
\hline $\begin{array}{l}\text { Total number of outpatient visits in } \\
\text { the past } 12 \text { months }\end{array}$ & $16.2 \pm 11.6$ & $13.9 \pm 10.0$ & 0.21 & $15.9 \pm 11.5$ & $15.9 \pm 10.9$ & 0.0003 \\
\hline Middle tertile & 27.5 & 29.2 & 0.04 & 27.8 & 27.9 & 0.001 \\
\hline Top tertile & 45.3 & 31.5 & 0.29 & 44.0 & 44.1 & 0.003 \\
\hline Psychotic psychiatric disease ${ }^{\S, f}$ & 9.5 & 4.2 & 0.21 & 8.5 & 8.4 & 0.005 \\
\hline Nonpsychotic psychiatric disease ${ }^{\S, \# \#}$ & 75.9 & 42.9 & 0.71 & 74.7 & 74.8 & 0.004 \\
\hline Benzodiazepine in the past 6 months & 38.3 & 17.9 & 0.47 & 35.6 & 35.4 & 0.004 \\
\hline $\begin{array}{l}\text { Oral/transdermal opioid } \\
\text { in the past } 6 \text { months }\end{array}$ & 35.1 & 22.5 & 0.28 & 33.3 & 33.1 & 0.004 \\
\hline $\begin{array}{l}\text { Smoking cessation drug } \\
\text { in the past } 12 \text { months }\end{array}$ & 2.9 & 1.7 & 0.08 & 2.6 & 2.5 & 0.007 \\
\hline
\end{tabular}

Data are presented as mean \pm SD or $\%$, unless otherwise stated. SSRI: selective serotonin reuptake inhibitor; SNRI: serotonin-noradrenaline reuptake inhibitor; COPD: chronic obstructive pulmonary disease; ICU: intensive care unit. \#: the full list of covariates included in the propensity score model can be found in the online supplementary material; " : standardised differences of $>0.10$ are thought to indicate potentially meaningful differences; ${ }^{+}$: a measure of patient morbidity burden, using hospitalisation and ambulatory visit data based on a 2-year look-back from the index date (Johns Hopkins ACG(r) System Ver XX); §: presence of comorbidities was based on 5-year look-back from the index date; ${ }^{f}$ : includes schizophrenia, bipolar disorder and paranoid states; \#\#: includes depression disorders, anxiety disorders, phobias, stress disorders, dissociative and somatisation disorders, eating disorders, personality disorders, mental and behavioural disorders due to

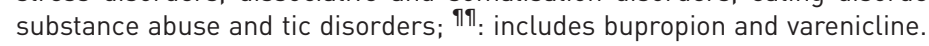

the setting of COPD is known to be associated with increased exacerbation risk and mortality [6, 7], we evaluated our outcomes stratifying by the presence of any physician-diagnosed psychiatric disease in the 5 years prior to the index date. These two sensitivity analyses evaluate outcomes across subgroups of 
differing COPD severity, thereby minimising possible healthy user bias (by examining outcomes in the sickest subgroup of individuals) and possible confounding by indication (by examining outcomes in the healthiest subgroup of individuals). Exposed and control individuals were matched at the index date on: the propensity score; COPD exacerbation frequency in the year prior to the index date; and psychiatric disease in the 5 years prior to the index date (the latter two variables were matched to facilitate our planned sensitivity analyses by these variables). Additional sensitivity analyses are presented in the online supplementary material.

\section{Statistical analysis}

Before and after propensity score matching, we calculated descriptive statistics with standardised differences for the exposed and control groups on all baseline covariates [39]. For all non-mortality outcomes, we used cause-specific hazard models to estimate the effect of SSRI/SNRI use on the hazard of the outcome after accounting for the competing risk of death. For COPD or pneumonia-related mortality, we used cause-specific hazard models to account for the competing risk of death due to other causes. For all-cause mortality, we used a Cox model to regress the cause-specific hazard of death on exposure status. SSRI/SNRI use was the sole independent variable in all models. For all models, a robust variance estimator was used to account for the matched nature of the sample [40] and hazard ratios (HRs) and 95\% confidence intervals were obtained. Number needed to harm $(\mathrm{NNH})$ was determined by calculating the inverse of the absolute risk difference (ARD). All statistical analyses were conducted using SAS Enterprise Guide 9.4.3 (SAS Institute, Cary, NC, USA).

\section{Results}

Between April 1, 2008 and December 31, 2013, 131718 older adults with COPD (118611 community-dwelling individuals and 13107 long-term care home residents) were identified. Of the 118 611 community-dwelling individuals, 29835 (25.2\%) were new SSRI/SNRI users (figure 1). After propensity score matching, 28360 new users were matched to an equivalent number of controls. No matched control was found for 1475 (4.9\%) of new SSRI/SNRI users. New users and controls were well balanced on baseline characteristics, with standardised differences $<10 \%$ for all variables (table 1 and online supplementary material). The long-term care home resident cohort analysis is presented in the online supplementary material.

Compared to non-users, new SSRI/SNRI users had significantly higher rates of hospitalisation for COPD or pneumonia (ARD 0.5\%; HR 1.15, 95\% CI 1.05-1.25; NNH 200), as well as ER visits for COPD or pneumonia (ARD 0.3\%; HR 1.13, 95\% CI 1.03-1.24; NNH 333), COPD or pneumonia-related mortality (ARD 0.1\%; HR 1.26, 95\% CI 1.03-1.55; NNH 1000) and all-cause mortality (ARD 0.8\%; HR 1.20, 95\% CI 1.11-1.29; NNH 125) (table 2). There was a significantly decreased rate of outpatient exacerbations among users (HR 0.91, 95\% CI 0.86-0.96) and there was no significant association with ICU admission during hospitalisation for COPD or pneumonia (HR 1.07, 95\% CI 0.85-1.34).

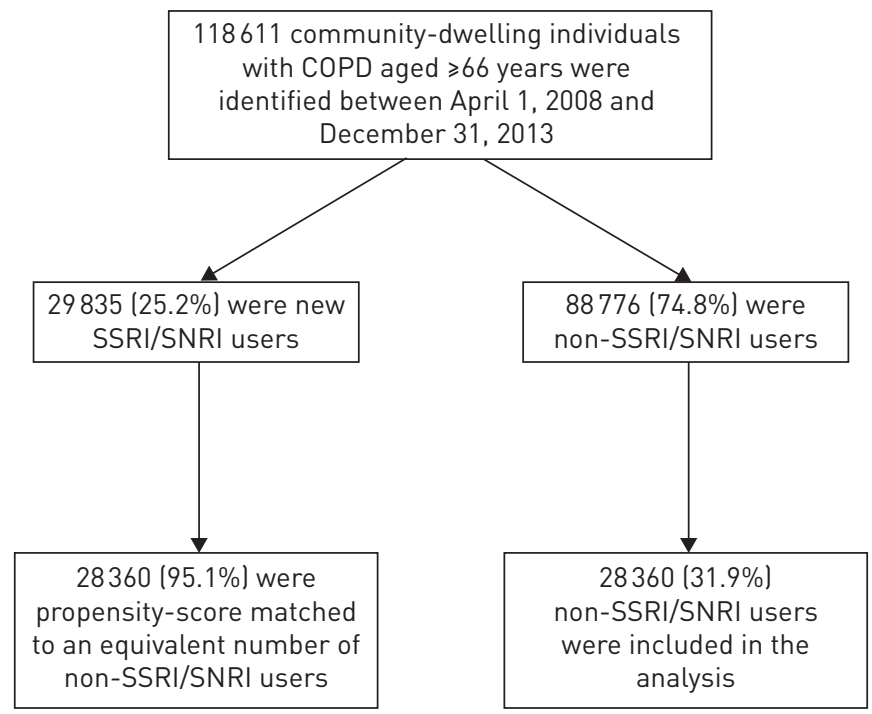

FIGURE 1 Flow diagram outlining exposed and control group identification in the community-dwelling cohort. COPD: chronic obstructive pulmonary disease; SSRI: selective serotonin reuptake inhibitor; SNRI: serotonin-noradrenaline reuptake inhibitor. 


\begin{tabular}{|c|c|c|c|}
\hline & Events & $\mathrm{HR}(95 \% \mathrm{CI})$ & p-value \\
\hline \multicolumn{4}{|c|}{ Outpatient respiratory exacerbation } \\
\hline New SSRI/SNRI users & $2406(8.5)$ & $0.91(0.86-0.96)$ & 0.0006 \\
\hline Non-SSRI/SNRI users & $2619(9.2)$ & Referent & \\
\hline \multicolumn{4}{|c|}{ ER visit for COPD or pneumonia } \\
\hline New SSRI/SNRI users & 918 (3.2) & $1.13(1.03-1.24)$ & 0.009 \\
\hline Non-SSRI/SNRI users & $812(2.9)$ & Referent & \\
\hline \multicolumn{4}{|c|}{ Hospital admission COPD or pneumonia } \\
\hline New SSRI/SNRI users & 1105 (3.9) & $1.15(1.05-1.25)$ & 0.002 \\
\hline Non-SSRI/SNRI users & $965(3.4)$ & Referent & \\
\hline \multicolumn{4}{|c|}{ ICU admission during a hospitalisation for COPD or pneumonia } \\
\hline New SSRI/SNRI users & $154(0.5)$ & $1.07(0.85-1.34)$ & 0.56 \\
\hline Non-SSRI/SNRI users & $144(0.5)$ & Referent & \\
\hline \multicolumn{4}{|c|}{ COPD or pneumonia-related mortality } \\
\hline New SSRI/SNRI users & 204 (0.7) & $1.26(1.03-1.55)$ & 0.03 \\
\hline Non-SSRI/SNRI users & $163(0.6)$ & Referent & \\
\hline \multicolumn{4}{|l|}{ All-cause mortality } \\
\hline New SSRI/SNRI users & $1355(4.8)$ & $1.20(1.11-1.29)$ & $<0.0001$ \\
\hline Non-SSRI/SNRI users & $1141(4.0)$ & Referent & \\
\hline
\end{tabular}

Data are presented as $\mathrm{n}(\%)$ unless otherwise stated. SSRI: selective serotonin reuptake inhibitor; SNRI: serotonin-noradrenaline reuptake inhibitor; ER: emergency room; COPD: chronic obstructive pulmonary disease; ICU: intensive care unit.

In the subgroup of individuals with no exacerbation in the year prior to the index date and those with $\geqslant 1$ outpatient respiratory exacerbation in the year prior to index, new versus non-users had significantly decreased rates of outpatient exacerbation (HR 0.80, 95\% CI $0.72-0.88$ and HR 0.90, 95\% CI 0.81-0.99, respectively) (table 3 ). In the subgroup of individuals with $\geqslant 1$ exacerbation requiring hospitalisation in the year prior to the index date, new versus non-users had significantly increased rates of hospitalisation for COPD or pneumonia (HR 1.23, 95\% CI 1.10-1.38) and COPD or pneumonia-related mortality (HR 1.45, 95\% CI 1.11-1.88), but these associations did not extend to other COPD exacerbation frequency subgroups. There were significantly increased rates of all-cause mortality among new versus non-users across all COPD exacerbation frequency subgroups (no exacerbation in the year prior to index HR 1.13, 95\% CI $1.01-1.27$; $\geqslant 1$ outpatient respiratory exacerbation in the year prior to index HR 1.33, 95\% CI $1.07-$ 1.66 ; $\geqslant 1$ exacerbation requiring hospitalisation in the year prior to index HR $1.23,95 \%$ CI $1.10-1.39$ ). No other associations were statistically significant.

In the subgroup of individuals without pre-existing psychiatric disease, new versus non-users had significantly increased rates of hospitalisation for COPD or pneumonia (HR 1.30, 95\% CI 1.10-1.54), ICU admission during hospitalisations for COPD or pneumonia (HR 1.81, 95\% CI 1.12-2.93), COPD or pneumonia-related mortality (HR 1.76, 95\% CI 1.21-2.55) and all-cause mortality (HR 1.71, 95\% CI 1.471.98) (table 4). In the subgroup of individuals with pre-existing psychiatric disease, new versus non-users had significantly decreased rate of outpatient exacerbation (HR 0.90, 95\% CI 0.85-0.96). No other associations were statistically significant.

\section{Discussion}

To our knowledge, our large, population-based study is the first to show that, among older adults with COPD, new users of SSRI or SNRI drugs have modest, but statistically significant, increases in rates of respiratory-related morbidity and mortality, as well as all-cause mortality, than controls matched on a wide range of covariates. The fact that similar results were found among subgroups of individuals with less severe COPD strengthens the credibility of our overall findings.

In the overall community-dwelling cohort, we found that new SSRI or SNRI use among older adults with COPD was associated with increased rates of various adverse events (i.e. ER visits, hospitalisations and death) and this consistency across a spectrum of outcomes strengthens the likelihood for a causal link between drug receipt and respiratory harm. While outpatient respiratory exacerbations were found to be significantly less frequent among new versus non-users, this result may be explained by the increased and competing risk of other adverse respiratory events (e.g. ER visits, hospitalisation) and death among new 
TABLE 3 Hazard ratios (HRs) and confidence intervals for outcomes in the propensity score matched community-dwelling cohort, stratified by chronic obstructive pulmonary disease (COPD) exacerbation frequency

\begin{tabular}{|c|c|c|c|c|c|c|c|c|c|c|c|c|c|c|c|c|c|c|}
\hline & \multicolumn{3}{|c|}{ Outpatient exacerbation } & \multicolumn{3}{|c|}{ ER visit for COPD or pneumonia } & \multicolumn{3}{|c|}{$\begin{array}{l}\text { Hospital admission COPD or } \\
\text { pneumonia }\end{array}$} & \multicolumn{3}{|c|}{$\begin{array}{l}\text { ICU admission during a } \\
\text { hospitalisation for COPD } \\
\text { or pneumonia }\end{array}$} & \multicolumn{3}{|c|}{$\begin{array}{c}\text { COPD or pneumonia-related } \\
\text { mortality }\end{array}$} & \multicolumn{3}{|c|}{ All-cause mortality } \\
\hline & Events & HR $(95 \% \mathrm{Cl})$ & $\mathrm{p}$-value & Events & HR $(95 \% \mathrm{Cl})$ & $p$-value & Events & HR $(95 \% \mathrm{Cl})$ & $\mathrm{p}$-value & Events & HR $(95 \% \mathrm{Cl})$ & $\mathrm{p}$-value & Events & HR $(95 \% \mathrm{Cl})$ & $\mathrm{p}$-value & Events & HR $(95 \% \mathrm{Cl})$ & $p$-value \\
\hline \multicolumn{19}{|l|}{$\begin{array}{l}0 \text { exacerbations in the year prior } \\
\text { to index }\end{array}$} \\
\hline New users & $704(4.2)$ & $\begin{array}{c}0.80 \\
(0.72-0.88)\end{array}$ & $<0.0001$ & $255(1.5)$ & $\begin{array}{c}1.14 \\
(0.95-1.36)\end{array}$ & 0.16 & $277(1.7)$ & $\begin{array}{c}0.98 \\
(0.83-1.15)\end{array}$ & 0.77 & $39(0.2)$ & $\begin{array}{c}0.83 \\
(0.54-1.27)\end{array}$ & 0.39 & $51(0.3)$ & $\begin{array}{c}1.14 \\
(0.76-1.70)\end{array}$ & 0.53 & $589(3.5)$ & $1.13(1.01-1.27)$ & 0.04 \\
\hline $\begin{array}{l}\text { Non-users } \\
\geqslant 1 \text { outpatient respiratory } \\
\text { exacerbation in the year prior } \\
\text { to index }\end{array}$ & $875(5.3)$ & & & $224(1.3)$ & & & $284(1.7)$ & & & $47(0.3)$ & & & $45(0.3)$ & & & $523(3.1)$ & & \\
\hline New users & $720(14.8)$ & $\begin{array}{c}0.90 \\
(0.81-0.99)\end{array}$ & 0.04 & $138(2.8)$ & $\begin{array}{c}1.25 \\
(0.97-1.60)\end{array}$ & 0.08 & $144(3.0)$ & $\begin{array}{c}1.20 \\
(0.94-1.53)\end{array}$ & 0.14 & $20(0.4)$ & $\begin{array}{c}1.54 \\
(0.76-3.10)\end{array}$ & 0.23 & $16(0.3)$ & $\begin{array}{c}0.73 \\
(0.39-1.40)\end{array}$ & 0.35 & $182(3.7)$ & $1.33(1.07-1.66)$ & 0.01 \\
\hline $\begin{array}{l}\text { Non-users } \\
\geqslant 1 \text { exacerbation requiring } \\
\text { presentation to hospital in } \\
\text { the year prior to index }\end{array}$ & 787 (16.2) & & & $111(2.3)$ & & & $120(2.5)$ & & & $13(0.3)$ & & & $22(0.5)$ & & & $138(2.8)$ & & \\
\hline New users & $982(14.3)$ & $\begin{array}{c}1.02 \\
(0.93-1.12)\end{array}$ & 0.66 & $525(7.6)$ & $\begin{array}{c}1.10 \\
(0.98-1.25)\end{array}$ & 0.11 & $684(10.0)$ & $\begin{array}{c}1.23 \\
(1.10-1.38)\end{array}$ & 0.0002 & $95(1.4)$ & $\begin{array}{c}1.13 \\
(0.84-1.52)\end{array}$ & 0.41 & $\begin{array}{l}137 \\
(2.0)\end{array}$ & $\begin{array}{c}1.45 \\
(1.11-1.88)\end{array}$ & 0.006 & $584(8.5)$ & $1.23(1.10-1.39)$ & 0.0006 \\
\hline Non-users & $957(13.9)$ & & & 477 (6.9) & & & $561(8.2)$ & & & $84(1.2)$ & & & $96(1.4)$ & & & $480(7.0)$ & & \\
\hline
\end{tabular}

Data are presented as $\mathrm{n}(\%)$, unless otherwise stated. ER: emergency room; ICU: intensive care unit.

TABLE 4 Hazard ratios (HRs) and confidence intervals for outcomes in the propensity score matched community-dwelling cohort, stratified by presence of pre-existing psychiatric disease ${ }^{\#}$

\begin{tabular}{|c|c|c|c|c|c|}
\hline Outpatient exacerbation & $\begin{array}{l}\text { ER visit for COPD or } \\
\text { pneumonia }\end{array}$ & $\begin{array}{c}\text { Hospital admission COPD or } \\
\text { pneumonia }\end{array}$ & $\begin{array}{l}\text { ICU admission during a } \\
\text { hospitalisation for COPD or } \\
\text { pneumonia }\end{array}$ & $\begin{array}{l}\text { COPD or pneumonia-related } \\
\text { mortality }\end{array}$ & All-cause mortality \\
\hline
\end{tabular}

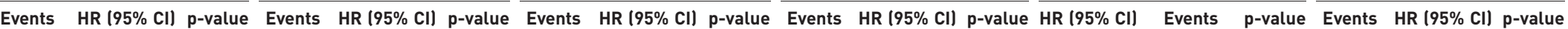

\begin{tabular}{|c|c|c|c|c|c|c|c|c|c|c|c|c|c|c|c|c|c|c|}
\hline \multicolumn{19}{|c|}{ No known pre-existing psychiatric disease } \\
\hline New users & $552(8.2)$ & $\begin{array}{c}0.92 \\
(0.82-1.04)\end{array}$ & 0.17 & 215 (3.2) & $\begin{array}{c}1.20 \\
(0.98-1.46)\end{array}$ & 0.07 & 307 (4.5) & $\begin{array}{c}1.30 \\
(1.10-1.54)\end{array}$ & 0.002 & $47(0.7)$ & $\begin{array}{c}1.81 \\
(1.12-2.93)\end{array}$ & 0.02 & $76(1.1)$ & $\begin{array}{c}1.76 \\
(1.21-2.55)\end{array}$ & 0.003 & $453(6.7)$ & $\begin{array}{c}1.71 \\
(1.47-1.98)\end{array}$ & $<0.0001$ \\
\hline Non-users & $594(8.8)$ & & & $180(2.7)$ & & & $237(3.5)$ & & & $26(0.4)$ & & & $44(0.7)$ & & & $270(4.0)$ & & \\
\hline \multicolumn{19}{|c|}{ Known pre-existing psychiatric disease } \\
\hline New users & $1854(8.6)$ & $\begin{array}{c}0.90 \\
(0.85-0.96)\end{array}$ & 0.002 & $703(3.3)$ & $\begin{array}{c}1.11 \\
(1.00-1.24)\end{array}$ & 0.05 & $798(3.7)$ & $\begin{array}{c}1.10 \\
(0.99-1.21)\end{array}$ & 0.06 & $107(0.5)$ & $\begin{array}{c}0.91 \\
(0.70-1.18)\end{array}$ & 0.46 & $128(0.6)$ & $\begin{array}{c}1.08 \\
(0.84-1.39)\end{array}$ & 0.55 & $902(4.2)$ & $\begin{array}{c}1.04 \\
(0.95-1.14)\end{array}$ & 0.41 \\
\hline Non-users & $2025(9.4)$ & & & $632(2.9)$ & & & $728(3.4)$ & & & $118(0.5)$ & & & $119(0.6)$ & & & $871(4.0)$ & & \\
\hline
\end{tabular}

Data are presented as $\mathrm{n}(\%)$, unless otherwise stated. ER: emergency room; COPD: chronic obstructive pulmonary disease; ICU: intensive care unit. \#: an individual was considered to have psychiatric disease if any one of the following conditions were present: schizophrenia, bipolar disorder, paranoid states, depression disorders, anxiety disorders, phobias, stress disorders, dissociative and somatisation disorders, eating disorders, personality disorders, mental and behavioural disorders due to substance abuse or tic disorders. 
users. In addition, the reduced rates of outpatient respiratory exacerbation observed may be as a result of SSRI/SNRI drugs (through their potentially deleterious respiratory effects) intensifying the severity of milder exacerbations or decreasing an individual's ability to cope with an exacerbation, thereby leading to an ER visit or hospital admission. While ICU admission during hospitalisations for COPD or pneumonia was not significantly associated with new SSRI/SNRI drug receipt, the relatively small numbers of individuals experiencing this specific outcome may explain this nonsignificant finding. We acknowledge that the absolute adverse event rates of our positive outcomes are relatively small, and therefore may not be clinically significant or they may not have remained positive had additional covariates been controlled for. However, our modestly elevated HRs may be clinically meaningful when one considers them at a population level. SSRI/SNRI drugs may lead to adverse respiratory outcomes among individuals with COPD thorough several possible mechanisms: by promoting sleepiness [15-19], which may then potentially lead to respiratory depression; by causing vomiting side-effects [15-19], which may then lead to aspiration (especially if fatigue and sleepiness are also present); by decreasing immune cell quantity and function [20-23]; and by reducing clearance of apoptotic cells in the airways, which may then lead to airway plugging [24, 25].

By balancing the exposed and control groups through propensity score matching on a large number of important and relevant variables (including multiple markers of COPD severity, multiple comorbidities, healthcare system utilisation, other prescription drug receipt and sociodemographic characteristics), the chances that our findings are explained by such factors are minimised. Selecting incident receipt of a non-SSRI/SNRI drug to define control group entry also served to decrease the likelihood that recent change in health status or differences in health-seeking behaviour explain our findings among exposed versus control individuals. Our main findings are strengthened by the fact that we observed increased rates of adverse outcomes among healthier subgroups of individuals with COPD, as these groups would be less likely to be influenced by confounding by indication. Specifically, we observed increased all-cause mortality in the subgroup of individuals with no prior respiratory exacerbation and we also found increased rates of morbidity and mortality among those without previously diagnosed psychiatric disease. The fact that increased rates of adverse events were not observed among new SSRI/SNRI recipients relative to controls among those with established psychiatric disease (and instead, a significantly decreased rate of outpatient exacerbations was found in the exposed group) may indicate that these drugs, when reasonably prescribed as treatment for mood disorder, facilitate more stable respiratory health, by potentially reducing depression and anxiety symptoms. In contrast, the finding of increased adverse respiratory outcomes among SSRI/ SNRI recipients without diagnosed psychiatric disease suggests risk for harm when these drugs are prescribed off-label, for reasons other than established psychiatric disease (e.g. treatment of insomnia, or mood symptoms where mood disorder criteria are not met).

Increased rates of negative respiratory events associated with SSRI/SNRI use were found to occur not only at higher drug dose levels, but extended even to lower drug dose levels (see online supplementary material 1 for this sensitivity analysis). However, the absence of clear dose-response relationship between SSRI/SNRI drugs and our outcomes raises the possibility of residual confounding influencing our results. Although we observed increased rates of respiratory-related morbidity and mortality in association with new SSRI/SNRI use among older adults with COPD, these drugs appear preferable from a respiratory safety perspective when compared head-to-head with benzodiazepines (see online supplementary material for this sensitivity analysis), which have similar prescribing indications and which we have previously found to be linked with increased risk of adverse respiratory outcomes in COPD [29].

As with all observational studies, a true causal link between SSRI/SNRI drug exposure and adverse outcomes cannot be concluded from our results alone. Our results could be influenced by residual confounding from unmeasured differences between the exposed and control groups. For example, we were unable to adjust for baseline respiratory or mood symptoms, smoking or lung function, as such clinical data were not available in our health administrative databases. We may not have eliminated from our analysis all individuals receiving palliative care using physician service codes and these individuals would have increased mortality risk. However, the residual inclusion of individuals receiving palliative care would unlikely explain our findings of increased ER visits and hospitalisations for COPD or pneumonia among the exposed group. While the identification of individuals with COPD in this study was based on a previously validated algorithm of health administrative codes, the classification of our outcomes (e.g. hospitalisation, mortality, etc.) as COPD- or pneumonia-related was not validated. Our findings may not apply to individuals with COPD aged $<66$ years, since these individuals were not included in our study. Finally, indication for SSRI/SNRI drug receipt was not available in our drug database. Nevertheless, we performed sensitivity analyses stratifying by COPD exacerbation frequency and by presence of psychiatric disease, and these analyses serve as proxies for drug indication. 


\section{Implications of findings for clinical practice}

Our findings should not be interpreted to indicate that use of SSRI/SNRI drugs should be avoided absolutely in individuals with COPD and comorbid psychiatric disease. Instead, our results should prompt prescribers to consider the potential for increased respiratory-related morbidity and mortality in SSRI/ SNRI prescribing decision making (especially when off-label drug use is being considered), to counsel patients about potential drug respiratory side-effects when prescribing SSRIs/SNRIs and to monitor for potential adverse respiratory effects when SSRI/SNRI drugs are initiated. Although SSRI/SNRI drugs were found to be associated with increased respiratory-related morbidity and mortality in this study, prescribers may want to consider using these medications to manage psychiatric symptoms over benzodiazepines, which appear to be associated with an even higher risk of adverse respiratory outcomes in COPD. Our findings also potentially highlight the importance of pursuing psychotherapy [41,42] and pulmonary rehabilitation [43] to help manage psychiatric disease in COPD, before turning to psychoactive medications.

In conclusion, new SSRI/SNRI drug use was associated with small, but significantly increased rates of respiratory-related morbidity and mortality among older adults with COPD. If this relationship is confirmed by future research, the potential for adverse respiratory outcomes may need to be considered when prescribing SSRI and SNRI drugs to older adults with COPD.

Acknowledgement: We thank Brogan Inc., Ottawa for use of their Drug Information Database.

Conflict of interest: D.E. O’Donnell reports grants and personal fees from Boehringer Ingelheim, AstraZeneca and GlaxoSmithKline, and personal fees from Novartis, Pfizer and Almirall, outside the submitted work.

Support statement: This research was funded by the University of Toronto, Pettit Respirology Block Term Grant. This study was supported by the Institute for Clinical Evaluative Sciences (ICES), which is funded by an annual grant from the Ontario Ministry of Health and Long-Term Care (MOHLTC). The opinions, results and conclusions reported in this paper are those of the authors and are independent from the funding sources. No endorsement by ICES or the Ontario MOHLTC is intended or should be inferred. Parts of this material are based on data and information compiled and provided by Canadian Institute for Health Information (CIHI). However, the analyses, conclusions, opinions and statements expressed herein are those of the author, and not necessarily those of CIHI. Parts of this material are based on data and information provided by Cancer Care Ontario (CCO). The opinions, results, view, and conclusions reported in this paper are those of the authors and do not necessarily reflect those of CCO. No endorsement by CCO is intended or should be inferred. P.C. Austin was supported in part by a Career Investigator Award from the Heart and Stroke Foundation. A.S. Gershon was supported in part by a Canadian Institutes of Health Research New Investigator Award. P.A. Rochon holds the Retired Teachers of Ontario/ERO Chair in Geriatric Medicine at the University of Toronto. Funding information for this article has been deposited with the Crossref Funder Registry.

\section{References}

1 Buist AS, McBurnie MA, Vollmer WM, et al. International variation in the prevalence of COPD (the BOLD Study): a population-based prevalence study. Lancet 2007; 370: 741-750.

2 Global Initiative for Chronic Obstructive Lung Disease (GOLD). Global Strategy for the Diagnosis, Management, and Prevention of Chronic Obstructive Pulmonary Disease. 2017. http://goldcopd.org/ gold-2017-global-strategy-diagnosis-management-prevention-copd/ Date last accessed: January 2018.

3 Kunik ME, Roundy K, Veazey C, et al. Surprisingly high prevalence of anxiety and depression in chronic breathing disorders. Chest 2005; 127: 1205-1211.

4 Miravitlles M, Molina J, Quintano JA, et al. Factors associated with depression and severe depression in patients with COPD. Respir Med 2014; 108: 1615-1625.

5 Pollack MH, Kradin R, Otto MW, et al. Prevalence of panic in patients referred for pulmonary function testing at a major medical center. Am J Psychiatry 1996; 153: 110-113.

$6 \mathrm{Ng} \mathrm{TP}$, Niti M, Tan WC, et al. Depressive symptoms and chronic obstructive pulmonary disease: effect on mortality, hospital readmission, symptom burden, functional status, and quality of life. Arch Intern Med 2007; 167: 60-67.

7 Eisner MD, Blanc PD, Yelin EH, et al. Influence of anxiety on health outcomes in COPD. Thorax 2010; 65: 229-234.

8 Lam RW, Kennedy SH, Grigoriadis S, et al. Canadian Network for Mood and Anxiety Treatments (CANMAT) clinical guidelines for the management of major depressive disorder in adults. III. Pharmacotherapy. $J$ Affect Disord 2009; 117: S26-S43.

9 Katzman MA, Bleau P, Blier P, et al. Canadian clinical practice guidelines for the management of anxiety, posttraumatic stress and obsessive-compulsive disorders. BMC Psychiatry 2014; 14: S1.

10 Usmani ZA, Carson KV, Cheng JN, et al. Pharmacological interventions for the treatment of anxiety disorders in chronic obstructive pulmonary disease. Cochrane Database Syst Rev 2011; 11: CD008483.

11 Evans M, Hammond M, Wilson K, et al. Placebo-controlled treatment trial of depression in elderly physically ill patients. Int J Geriatr Psychiatry 1997; 12: 817-824.

12 Lacasse Y, Beaudoin L, Rousseau L, et al. Randomised trial of paroxetine in end-stage COPD. Monaldi Arch Chest Dis 2004; 61: 140-147.

13 Eiser N, Harte R, Spiros K, et al. Effect of treating depression on quality-of-life and exercise tolerance in severe COPD. COPD 2005; 2: 233-241.

14 Yohannes AM, Connolly MJ, Baldwin RC. A feasibility study of antidepressant drug therapy in depressed elderly patients with chronic obstructive pulmonary disease. Int J Geriatr Psychiatry 2001; 16: 451-454. 
15 Cipriani A, La Ferla T, Furukawa TA, et al. Sertraline versus other antidepressive agents for depression. Cochrane Database Syst Rev 2010; 4: CD006117.

16 Magni LR, Purgato M, Gastaldon C, et al. Fluoxetine versus other types of pharmacotherapy for depression. Cochrane Database Syst Rev 2013; 7: CD004185.

17 Purgato M, Papola D, Gastaldon C, et al. Paroxetine versus other anti-depressive agents for depression. Cochrane Database Syst Rev 2014; 4: CD006531.

18 Cipriani A, Purgato M, Furukawa TA, et al. Citalopram versus other anti-depressive agents for depression. Cochrane Database Syst Rev 2012; 7: CD006534.

19 Cipriani A, Koesters M, Furukawa TA, et al. Duloxetine versus other anti-depressive agents for depression. Cochrane Database Syst Rev 2012; 10: CD006533.

20 Pellegrino TC, Bayer BM. Specific serotonin reuptake inhibitor-induced decreases in lymphocyte activity require endogenous serotonin release. Neuroimmunomodulation 2000; 8: 179-187.

21 Fazzino F, Montes C, Urbina M, et al. Serotonin transporter is differentially localized in subpopulations of lymphocytes of major depression patients. Effect of fluoxetine on proliferation. J Neuroimmunol 2008; 196: 173-180.

22 Taler M, Gil-Ad I, Lomnitski L, et al. Immunomodulatory effect of selective serotonin reuptake inhibitors (SSRIs) on human T lymphocyte function and gene expression. Eur Neuropsychopharmacol 2007; 17: 774-780.

23 Shenoy AR, Dehmel T, Stettner M, et al. Citalopram suppresses thymocyte cytokine production. J Neuroimmunol 2013; 262: 46-52.

24 Tanaka T, Doe JM, Horstmann SA, et al. Neuroendocrine signaling via the serotonin transporter regulates clearance of apoptotic cells. J Biol Chem 2014; 289: 10466-10475.

25 Vandivier RW, Henson PM, Douglas IS. Burying the dead: the impact of failed apoptotic cell removal (efferocytosis) on chronic inflammatory lung disease. Chest 2006; 129: 1673-1682.

26 Gershon AS, Wang C, Guan J, et al. Identifying individuals with physician diagnosed COPD in health administrative databases. COPD 2009; 6: 388-394.

27 Levy R, O’Brien BJ, Sellors C, et al. Coding accuracy of administrative drug claims in the Ontario Drug Benefit database. Can J Clin Pharmacol 2003; 10: 67-71.

28 Gershon AS, Wang C, Wilton AS, et al. Trends in chronic obstructive pulmonary disease prevalence, incidence, and mortality in Ontario, Canada, 1996 to 2007: a population-based study. Arch Intern Med 2010; 170: 560-565.

29 Vozoris NT, Fischer HD, Wang X, et al. Benzodiazepine drug use and adverse respiratory outcomes among older adults with COPD. Eur Respir J 2014; 44: 332-340.

30 Vozoris NT, Wang X, Fischer HD, et al. Incident opioid drug use and adverse respiratory outcomes among older adults with COPD. Eur Respir J 2016; 8: 683-693.

31 Canadian Pharmacists Association. Compendium of Pharmaceuticals and Specialties. Ottawa, Canadian Pharmacists Association, 2013.

32 Austin PC. An introduction to propensity score methods for reducing the effects of confounding in observational studies. Multivariate Behav Res 2011; 46: 399-424.

33 Austin P. Statistical criteria for selecting the optimal number of untreated subjects matched to each treated subject when using many-to-one matching on the propensity score. Am J Epidemiol 2010; 172: 1092-1097.

34 Austin PC. Optimal caliper widths for propensity-score matching when estimating differences in means and differences in proportions in observational studies. Pharm Stat 2011; 10: 150-161.

35 Donaldson GC, Seemungal TA, Bhowmik A, et al. Relationship between exacerbation frequency and lung function decline in chronic obstructive pulmonary disease. Thorax 2002; 57: 847-852.

36 Spencer S, Calverley PM, Burge PS, et al. Impact of preventing exacerbations on deterioration of health status in COPD. Eur Respir J 2004; 23: 698-702.

37 Hurst JR, Vestbo J, Anzueto A, et al. Susceptibility to exacerbation in chronic obstructive pulmonary disease. N Engl J Med 2010; 363: 1128-1138.

38 Connors AF Jr, Dawson NV, Thomas C, et al. Outcomes following acute exacerbation of severe chronic obstructive lung disease. The SUPPORT investigators (Study to Understand Prognoses and Preferences for Outcomes and Risks of Treatments). Am J Respir Crit Care Med 1996; 154: 959-967.

39 Austin PC. Balance diagnostics for comparing the distribution of baseline covariates between treatment groups in propensity-score matched samples. Stat Med 2009; 28: 3083-3107.

40 Austin PC. The performance of different propensity score methods for estimating marginal hazard ratios. Stat Med 2013; 32: 2837-2849.

41 Usmani ZA, Carson KV, Heslop K, et al. Psychological therapies for the treatment of anxiety disorders in chronic obstructive pulmonary disease. Cochrane Database Syst Rev 2017; 3: CD010673.

42 Farver-Vestergaard I, O’Toole MS, O'Connor M, et al. Mindfulness-based cognitive therapy in COPD: a cluster randomised controlled trial. Eur Respir J 2018; 51: 1702082.

43 Hill K, Geist R, Goldstein RS, et al. Anxiety and depression in end-stage COPD. Eur Respir J 2008; 31: 667-677. 